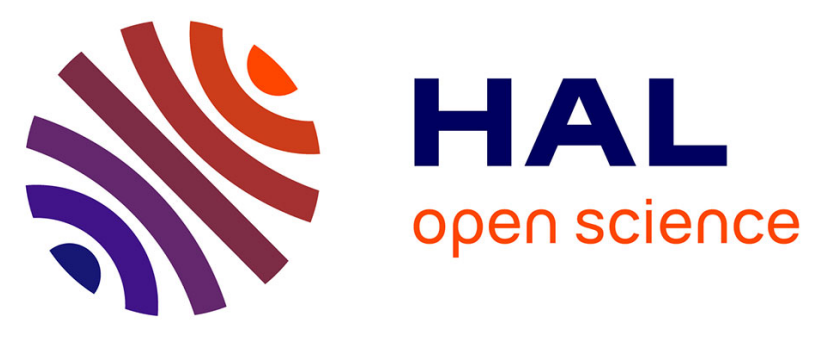

\title{
Experimental investigations on the process of forming functional microstructured blades from highly filled thermoplastic composites prepared with $\mathrm{La}(\mathrm{Fe}, \mathrm{Si}) 13$ alloys
}

Julien Lanzarini, Mohamed Lakdhar Sahli, Thierry Barriere, Alexandra

Dubrez, Charlotte Mayer, Michel Pierronnet, Peter Vikner

\section{To cite this version:}

Julien Lanzarini, Mohamed Lakdhar Sahli, Thierry Barriere, Alexandra Dubrez, Charlotte Mayer, et al.. Experimental investigations on the process of forming functional microstructured blades from highly filled thermoplastic composites prepared with $\mathrm{La}(\mathrm{Fe}, \mathrm{Si}) 13$ alloys. Journal of Materials Processing Technology, 2019, 273, pp.116244 (12). hal-02867771

\section{HAL Id: hal-02867771 \\ https://hal.science/hal-02867771}

Submitted on 26 Oct 2021

HAL is a multi-disciplinary open access archive for the deposit and dissemination of scientific research documents, whether they are published or not. The documents may come from teaching and research institutions in France or abroad, or from public or private research centers.
L'archive ouverte pluridisciplinaire HAL, est destinée au dépôt et à la diffusion de documents scientifiques de niveau recherche, publiés ou non, émanant des établissements d'enseignement et de recherche français ou étrangers, des laboratoires publics ou privés.

\section{(ㄷ)(1) $\$$}

Distributed under a Creative Commons Attribution - NonCommerciall 4.0 International 
Version of Record: https://www.sciencedirect.com/science/article/pii/S0924013619302080

Manuscript_e5ffdcdff9bb93e415296ad8bb31c6e4

Revised paper with red colours in the text (our responses to reviewer) and in blue colour used by Elsevier language service for English corrections. Please only used for reviewing

\begin{abstract}
Highly loaded polymer extrusion and forming processes are low-cost manufacturing processes which use continuous polymer profiles to elaborate magnetocaloric composites and $2 \mathrm{D}$ structured thin components and shape them into a wide variety of materials. The development of functional composites involves various requirements, specifications, and composite component designs. A composite must exhibit a high shear viscosity for polymer extrusion processing and permit extremely high loadings of solids to produce functional magnetocaloric properties which are equivalent to those of bulk materials. A composite material based on highly loaded magnetocaloric composites was elaborated and investigated by using gas-atomised $\mathrm{La}(\mathrm{Fe}, \mathrm{Si})_{13}$ alloys. This proposed solution appears to be useful in the fabrication of functional structured magnetocaloric components as regenerators or blade shapes. In the present study, composite elaborations were investigated with specific focus on the homogeneity and rheological behaviours for a powder size distribution between 13 and $143 \mu \mathrm{m}$, solid loadings of $35 \%$ to $65 \%$ by volume, and shear rates of $10^{2}$ to $10^{3} / \mathrm{s}$. The binder used was based on different thermoplastic polymers with low melting temperatures, such as polypropylene or low-density polyethylene, to avoid dehydrogenation of the magnetocaloric powders during the material-forming process. The shaping of structured blades by highly loaded polymer processing from the compounding to the forming process through the development of innovative processes and dedicated extrusion lines equipped with well-designed microstructured thin-blade-forming tools was studied. Thin structured blades of thickness 0.5 mm were obtained with micropatterns of width $200 \mu \mathrm{m}$, with the maximal efficiency being 92\%. The Curie temperature was determined from the powder stage to the mixing process and the final material shaping to validate the magnetocaloric properties and quantify the limits of the methodologies developed with different powders (the Curie temperature was adjusted to -21 and $23.5^{\circ} \mathrm{C}$ ). In this regard, the elaborated composite and the structured thin extruded component were characterised in terms of the homogeneity, magnetocaloric properties, and dimensional and geometric tolerances.
\end{abstract}

Keywords: Magnetocaloric effect; Curie temperature; $\mathrm{La}(\mathrm{Fe}, \mathrm{Si})$ alloy; polymer micro-extrusion; forming processes; highly loaded polymer; surface micro-structuration replication. 
Experimental investigations on the process of forming functional microstructured blades from highly filled thermoplastic composites prepared with $\mathrm{La}(\mathrm{Fe}, \mathrm{Si})_{13}$ alloys

J. Lanzarini ${ }^{(1)}$, M. Sahli (1), T. Barriere ${ }^{(1)}$, A. Dubrez ${ }^{(2)}$, C. Mayer ${ }^{(2)}$, M. Pierronnet ${ }^{(2)}$ and P. Vikner $^{(2)}$ UBFC, Femto-ST Institute, Department of Applied Mechanics, 24 Rue de l'Epitaphe, 25030 Besançon, France ${ }^{(1)}$ Erasteel SAS, Tour Maine Montparnasse, 33 avenue du Maine, 75755 Paris Cedex 15, France ${ }^{(2)}$

Corresponding author:

\section{BARRIERE Thierry}

Univ. Bourgogne Franche-Comté, FEMTO-ST Institute, CNRS/UFC/ENSMM/UTBM, Department of Applied Mechanics, 25000 BESANÇON-FR

Tel: (+33) 381666015

E-mail: thierry.barriere@univ-fcomte.fr

\section{Introduction}

Refrigeration is an essential aspect of our daily lives, covering applications from cooling and heating in the foodprocessing industry to air conditioning and refrigeration. Cooling must progress toward more environmentally friendly technologies to reduce the consumption of electricity. Indeed, present-day cooling systems are based on the thermodynamic principle of gas compression and expansion, which is harmful to the environment. Freon, which belongs to the hydrochlorofluorocarbon family, damages the ozone layer. Meinshausen et al. (2009) revealed that these fluids can be replaced by hydrofluorocarbons, which are harmless to the ozone layer. However, they are powerful greenhouse gases. Duarte et al. (2015) conducted experiments by considering new natural refrigerants such as water vapour, air, carbon dioxide, ammonia, and hydrocarbons. However, their use in domestic refrigeration is complicated. 
All these efforts to reduce the energy consumption associated with cooling are inadequate. Current research activities therefore aim to find solutions to reduce the environmental impact of conventional cooling systems. Franco et al. (2018) analysed different promising solutions for room temperature applications by using magnetic refrigeration. From a thermodynamic perspective, magnetic refrigeration displays high efficiency because of the reversibility of the magnetization and demagnetization cycle and avoidance of the use of polluting gases. Energy consumption and the emission of greenhouse gases can be reduced.

Tishin et al. (2003) investigated the magnetic refrigeration technology for cooling by using a magnetocaloric material and heat transfer fluid which is based on the magnetocaloric effect (MCE) with an active magnetic regenerator (AMR) system. Gschneidner et al. (2005) measured the different specific MCE values of the material which heats or cools when magnetized or demagnetized. The MCE effect is maximal around a temperature identified as that at which the critical order-disorder transition occurs, which corresponds to the $\mathrm{T}_{\mathrm{c}}$ (Curie temperature). There are many materials capable of exhibiting MCE. Dan'Kov et al. (1998) specifically investigated Gd to validate the proof of concept of magnetic refrigeration through some innovative prototypes for AMRs. Gd and its derivatives reveal efficient performances around room temperature. From environmental and economic points of view, they contain rare earths which are not suitable for industrial-scale production. They exhibit toxicity and are expensive. Other materials are more suitable for industrial application because of high efficiency and low cost. Brück et al. (2004) used Mn and its various compounds $\left(\mathrm{MnFeP}_{1-\mathrm{x}} \mathrm{As}_{\mathrm{x}}\right)$ for room-temperature magnetic refrigeration applications, but they contain toxic substances such as As.

Given this context, in our current study, it is important to use materials which exhibit nontoxic life cycles and are resource-efficient, including such alloys as the FeSiLa family. FeSiLa alloys are among the most promising for magnetic refrigeration and have already demonstrated high performances around the $\mathrm{T}_{\mathrm{c}}$. Yang et al. (2018) proposed a specific method to simultaneously elaborate the $\mathrm{La}(\mathrm{Fe}, \mathrm{Si})_{13}$ plate formed by mixing hydride $\mathrm{MgNiYHx}$ and Sn3.0Ag0.5Cu powders. Pengna et al. (2017) obtained a large magnetic entropy change of $13.5 \mathrm{~J} / \mathrm{kg} / \mathrm{K} \mathrm{for} \mathrm{LaFe}_{11.6} \mathrm{Si}_{1.4}$ without a post-annealing process at an imposed external magnetic field of 2 Tesla. Rosendahl et al. (2010) investigated a novel powder metallurgy process of modifying the $T_{c}$ of magnetic refrigerants for room temperature magnetic applications. The $\mathrm{T}_{\mathrm{c}}$ can be adjusted for applications near room temperature. These alloys are composed of abundant and nontoxic elements such as Fe, therefore, they can be fabricated on a large-scale at moderate costs. They display some disadvantages, such as sensitivity to oxidation, which are a result of the delicate nature of the synthesis process. Phejar et al. (2010) used these alloys, which are usually brittle materials with complicated manufacturing processes, in their investigations. 
In our previous work, a thermoplastic highly loaded with gas-atomised $\mathrm{La}(\mathrm{Fe}, \mathrm{Si})_{13}$ magnetocaloric powder was investigated (Lanzarini et al. (2015)), and their rheological behaviours suggested enhanced processability in injectionmoulding processes. The $\mathrm{T}_{\mathrm{c}}$ control as a function of the elaboration temperature (mixing temperature) constrained the application of the magnetocaloric powder. The temperature limit was equal to $200{ }^{\circ} \mathrm{C}$ to avoid dehydrogenation of the magnetocaloric powders; this was determined by Ma et al. (2014). This approach seems to be promising for the application of functionally structured magnetocaloric components as regenerators.

In the present study, a composite material obtained through highly loaded magnetocaloric extrusion processes was investigated with gas-atomised $\mathrm{La}(\mathrm{Fe}, \mathrm{Si})_{13}$ alloys. To realise the development of and analyse the functional magnetocaloric properties, twin-screw extruder equipment was used to elaborate the composite according to different formulations of thermoplastic polymers and magnetocaloric powders. Thermoplastic polymers are easy to utilise and permit the use of shaping methods such as extrusion process and the reduction of oxidation sensitivity by employing a polymer with a low fusion temperature. Prototypes of magnetic refrigerators were developed based on the AMR cycle, in which the magnetocaloric components are one of the key elements. They can exhibit different geometries, such as blades. Tura et al. (2012) studied the AMR cycle for some Gd blade-shaped regenerators. This 2D profile shape was adapted to the extrusion process, which rendered the realisation of a continuously structured thin profile possible, depending on the desired geometry involving different comb-like geometries. Wieland et al. (2017) obtained a wall thickness of less than $300 \mu \mathrm{m}$ by extrusion. A composite formulation was developed according to the shaping process for different polymer compositions, powder volume loadings, and magnetocaloric powders. The purpose is to improve the shaping of the magnetocaloric components (structured thin blades) by using the tailored composite materials fabricated by extrusion to study the geometrical limit and tolerance of the microstructure. The development, the results of the investigation, and the limit of innovative extrusion lines equipped with well-designed microstructured thin-bladeforming tools are also presented. The elaborated composite and the structured thin extruded component were characterised in terms of the homogeneity, magnetocaloric properties, and dimensional and geometric tolerances.

Rheological analysis highlighted the potential use of this composite as a processing material in the extrusion process to elaborate some structured magnetocaloric components with appropriate magnetocaloric properties. Experiments based on different processing parameters were carried out for fabricating continuous microstructured thin and highly loaded polymer profiles. An extrusion line was designed at the same time for characterisation of the composite. This extrusion line used a single-screw extruder. An inadequate process often leads to extruded components exhibiting poor shapes and material inhomogeneities. To verify the efficiency of this approach, the composite and the structured extruded components were characterised in terms of their homogeneity, magnetocaloric properties, and dimensional and geometric tolerances with different powders in terms of the $\mathrm{T}_{\mathrm{c}}$ (which was adjusted to -21 and $23.5{ }^{\circ} \mathrm{C}$ ). $\mathrm{The}^{\mathrm{T}} \mathrm{T}_{\mathrm{c}}$ was 
evaluated by differential scanning calorimetry (DSC) measurements, and the stability of the $\mathrm{T}_{\mathrm{c}}$ improved from the powders to the magnetocaloric elaborated composites and structured magnetocaloric components. The value of Tc was used for quality control to ensure non-degradation of the MCE, which can degrade during the processing method developed. The adiabatic variation in temperature, $\Delta \mathrm{T}$, under the action of an imposed magnetic field is one of the characteristic variables of the MCE. The $\Delta \mathrm{T}$ is quantified by a direct method below 1 Tesla. The scope of this research was extended by studying the influence of the powder loading on the efficiency of the extruded structured-thin-blade.

\section{Experimental methods and materials}

\subsection{Principles of extrusion and forming processes}

The process of elaboration of composite blades is divided into two sequential stages:

1. Elaboration of the composite by polymer extrusion: The highly loaded magnetocaloric powders are mixed with a thermoplastic polymer by using a twin-screw mixer or through extrusion. The composite with different formulations is in granular form.

2. Shaping by extrusion: The composite is shaped and calibrated to obtain functional magnetocaloric structured components by extrusion with the help of dedicated forming tools.

Magnetocaloric composite blends were developed during compounding by using a corotating twin-screw extruder. This equipment allows for continuous elaboration of the material composite. This extruder uses two modular screws built from individual screw elements such as conveying and kneading elements. Breitenbach (2002) reviewed the melt extrusion process for specific elements. These elements were organised according to the desired application. In our study, the profile screw used was adapted to prepare a mixture of thermoplastics filled with highly loaded magnetocaloric powders; this screw was previously used by Villmow et al. (2010) to elaborate polycaprolactone/multiwalled carbon nanotube composites.

The shaping process involves extrusion of the magnetocaloric composite prepared by twin-screw extrusion to obtain microstructured components. This stage involves a single-screw extruder equipped with a microstructured blade die at its head and a series of tools. The complexity and size of the die profile can generate a high pressure at the head of the extruder. The single-screw extruder equipment offers the advantage of a higher pressure, compared with that obtained with the twin-screw extruder configuration, but it is less suitable for elaborating highly loaded mixtures. The composite is extruded through a die of a fixed cross-sectional profile to produce the extrudate. It flows through a sizer, which calibrates the composite to realise the final structured components. The extruded profile is cooled in a water bath and then extracted by using a puller. The development of this process is more complex than the preparation of magnetocaloric composites. Indeed, the tool design is difficult. It depends on the material used and the dimensions of the desired component. 


\subsection{Material characteristics}

Gas atomisation technology is an efficient method of producing magnetocaloric powders with a specific spherical shape and smaller particle size distributions. It has recently been applied to magnetocaloric powders by Mayer et al. (2014); in particular, Dubrez et al. (2013) applied it to the magnetocaloric powder of $\mathrm{La}(\mathrm{Fe}, \mathrm{Si})_{13}$. This is a breakthrough technology which permits low-cost mass production of powders in large volumes. In an inert atmosphere, the powder material is annealed between 600 and $1300{ }^{\circ} \mathrm{C}$ to form a magnetocaloric phase with cubic structure, such as $\mathrm{NaZn}_{13}$. In a hydrogenous atmosphere, thermal treatments were carried out to insert $\mathrm{H}$ into the $\mathrm{NaZn}_{13}$ phase. In the final state, the powders are ground to achieve smaller particle size distributions. The gas-atomised magnetocaloric powders display a density equal to $7.3 \mathrm{~g} / \mathrm{cm}^{3}$. The two different grades (A1 and A2) of the magnetocaloric $\mathrm{La}(\mathrm{Fe}, \mathrm{Si})_{13}$ powders, which differ in their Curie temperatures, which are -21 and $23.5{ }^{\circ} \mathrm{C}$, respectively, exhibit the same morphology and granulometry. Laser diffraction was used for determination of the particle size distribution, and $\mathrm{d}_{10}$, $\mathrm{d}_{50}$, and $\mathrm{d}_{90}$ are commonly used to represent the median and range of the particle sizes of a given sample based on the cumulative volume percentages; these values are equal to $\left(d_{10}\right) 13,\left(d_{50}\right) 52$, and $\left(d_{90}\right) 143 \mu \mathrm{m}$. The Brunauer, Emmett, and Teller method with $\mathrm{Kr}$ gas was used to evaluate the specific surface area (SSA). The SSA is equal to $0.0709 \mathrm{~m}^{2} / \mathrm{g}$, and this low value is less than the $0.2 \mathrm{~m}^{2} / \mathrm{g}$ required for facilitating the combining of the mixing stage with maximal solid loading.

The binders used in the preparation of the magnetocaloric composite were thermoplastic polymers composed of polypropylene (PP) or low-density polyethylene (LDPE). The PP selected for our study displays a melt flow rate (MFR) of $11 \mathrm{~g} / \mathrm{min}\left(230{ }^{\circ} \mathrm{C}, 2.16 \mathrm{~kg}\right)$ and a density of $0.905 \mathrm{~g} / \mathrm{cm}^{3}$. The LDPE studied exhibits a MFR of $22 \mathrm{~g} / \mathrm{min}\left(190{ }^{\circ} \mathrm{C}\right.$, $2.16 \mathrm{~kg}$ ) and the density equals $0.919 \mathrm{~g} / \mathrm{cm}^{3}$.

Thermal analysis of each polymer component was performed by thermogravimetric analysis (TGA) and DSC. TGA was performed first, prior to DSC analyses based on ASTM methods. The analyser SETSYS Evolution TGA was used to evaluate the degradation temperature of each component of the polymer binders (LDPE and PP). In nitrogen atmosphere, the TGA patterns were obtained from room temperature to $450{ }^{\circ} \mathrm{C}$ at the heating and cooling rate of 2 ${ }^{\circ} \mathrm{C} / \mathrm{min}$. To confirm the repeatability of the experiments, each test was performed twice at the same heating rate. For PP and LDPE, the thermal degradation temperatures were $390 \pm 1$ and $410 \pm 1{ }^{\circ} \mathrm{C}$, respectively.

The melting temperature of each binder component was evaluated by using A Model 92 calorimeter. In nitrogen atmosphere, the tests were performed from room to the degradation temperatures at the same heating rate. The melting temperature of the polymer was determined from the DSC graph, and the obtained value was used in the rheology tests and in adjusting the mixing parameters. The DSC graphs of the binders are plotted in Figure 1, and, according to the endothermic peak positions, the melting temperatures of LDPE and PP are $110 \pm 1$ and $155 \pm 1{ }^{\circ} \mathrm{C}$, respectively. 


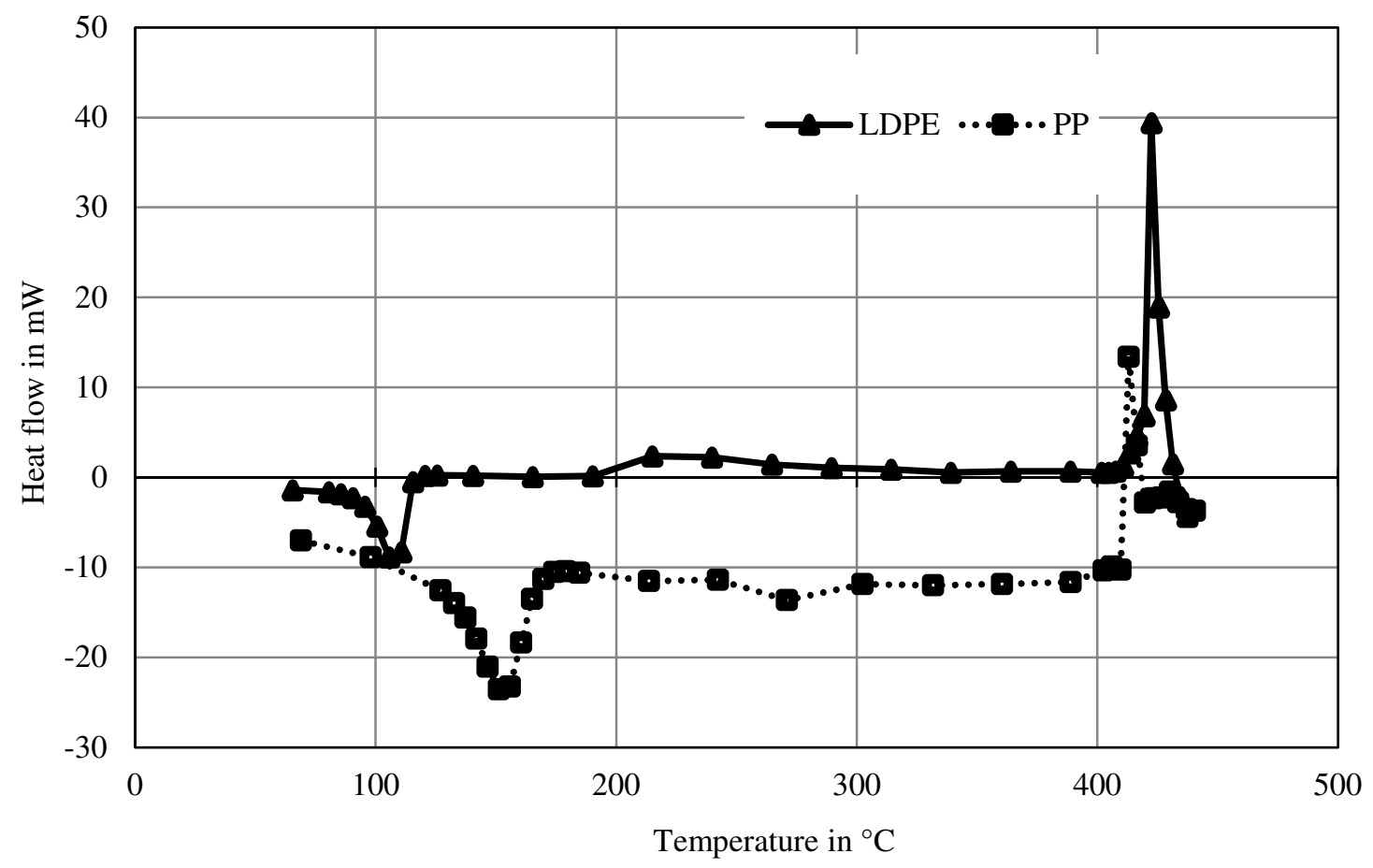

Fig. 1. Determination of the melting temperatures of PP and LDPE by DSC

The mixing temperatures of the powder and binder systems were obtained by using the DSC results and considering the melting temperature of the polymer and chosen as $140{ }^{\circ} \mathrm{C}$ for LDPE and $180{ }^{\circ} \mathrm{C}$ for PP; these temperatures are below the degradation temperatures of the two polymers. The mixing temperatures of the powders and polymer were so chosen to achieve optimal homogenisation efficiency of all the components and prevent binder degradation. In conclusion, the polymer retained must preserve the magnetocaloric properties of the powder with melting temperature below $200{ }^{\circ} \mathrm{C}$ to avoid dehydrogenation of the magnetocaloric powders. The preceding result was in agreement with the degradation temperatures obtained by Mayer et al. (2014) for the same powders.

\subsection{Magnetocaloric feedstock elaboration}

Elaboration of the composite by extrusion is commonly used in compounding during plastic manufacturing, and was previously employed by Cheng et al. (1997). This process continuously supplies homogeneous, highly loaded mixtures through a system of a corotating twin screws. The equipment used a modular screw profile (length-to-diameter ratio $\mathrm{L} / \mathrm{D}=40$, diameter $\mathrm{D}=16 \mathrm{~mm}$ ). The maximal torque and pressure were $120 \mathrm{Nm}$ and $10 \mathrm{MPa}$, respectively. The configuration of the element screw produced conveying, melting, kneading, and pumping zones, as shown in Fig. 2. The thermoregulated barrel contained two feeding areas and could be regulated in the temperature range 20 to $400{ }^{\circ} \mathrm{C}$. During the processing, the data were recorded to determine the influence of the processing parameters on the die 
pressure and the screw torque curves. The powder and binder were supplied by a weight and volumetric feeder, respectively. The polymer was first introduced through the inlet of the feed hopper extruder. The temperature setting enabled the transition of the polymer into the melt state; the polymer was conveyed by the screws. Then, the magnetocaloric powders were introduced. The elaborated composite was conveyed, and it flowed to the die at the extruder outlet. The composite exited from the cylindrical die and was cut to granules.

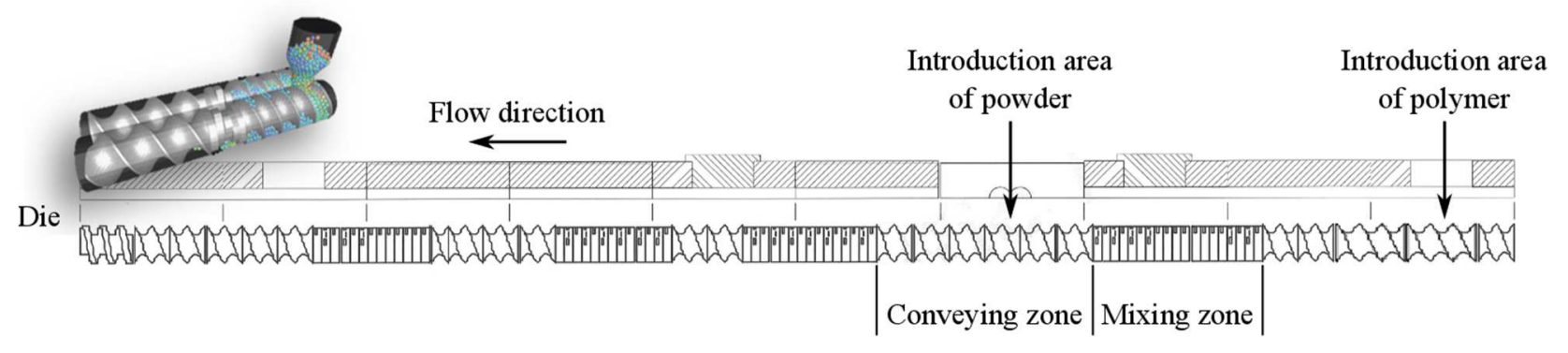

Fig. 2. Compounding screw profile with kneading and conveying elements

The critical parameters of the highly loaded polymer extrusion process are the high pressure in the die and the high mixing torque on the screws. The procedure was iterative. First, the temperature and screw speed were set. The feeders were programmed according to the composite formulation. The process started with a low powder flow (low powder loadings by volume). This flow increased progressively, which resulted in increases in the mixing torque and the pressure. Liang et al. (2002) obtained the same experimental results under different processing conditions. These phenomena are explained in terms of the physical behaviour, which is determined by the flow properties and processing parameters: the increase in the feedstock viscosity and the increase in the volume occupied by the magnetocaloric powder in the elaborated composite present in the screw-barrel system. Akdogan (1996) used the same extrusion methodology. The screw speed was increased to reduce the screw torque. After stabilisation, the powder loading was increased again, and the entire process repeated. The barrel temperature profile could be increased to reduce the relative shear viscosity and decrease the mixing torque. Maximal powder loading was achieved when the process could not further reduce the mixing torque. At this stage, the equipment limitations are reached in terms of the torque values and fill rate of the screws.

The aim was to develop a stable extrusion process for the preparation of a homogeneous composite based on a thermoplastic highly loaded with magnetocaloric powders. During extrusion, different associated parameters, such as the mixing temperature, screw speed, and material feeding (powder and binder), required optimisation to determine the highest powder loading by volume. In this study, a previous iterative mixing procedure was applied to quantify the maximal powder loading by volume associated with the composite formulations F1 and F2 and the magnetocaloric powders A1 and A2. 


\subsection{Shaping by extrusion}

The transformation of magnetocaloric materials is not easy. Current magnetic refrigerator prototypes incorporate thin structured blade components of magnetocaloric materials. Extrusion of molten polymers is one of the most commonly used processes for obtaining continuous thermoplastic profiles and was chosen to realise large-scale magnetic refrigeration and overcome the difficulties associated with the transformation. A tooling line for shaping was developed by extrusion of the magnetocaloric composite. Therefore, the extrusion-forming tools were specifically developed to elaborate a continuous thin-structured blade with the geometry proposed in Fig. 3.
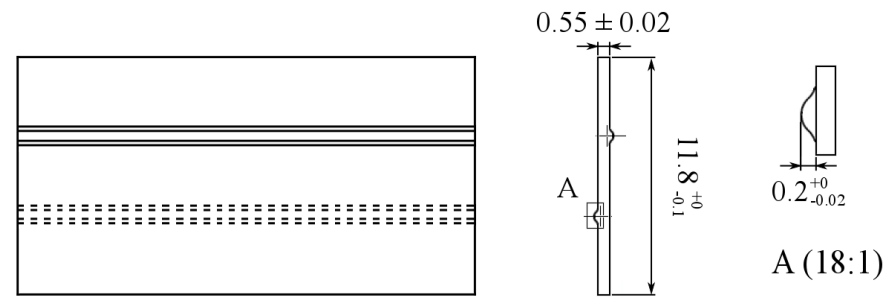

Fig. 3. Geometry of the microstructured magnetocaloric component

The extrusion-forming tools consisted of four elements between the extruder and the puller: a structured profile die, sizer, water cooling bath, and dryer system (Figure 4). The microstructured die was fixed to the extremity of the extruder. It allowed melt forming of the highly loaded composite. Experience showed that the dimension of the blade profile of the die was wider than that of the desired component. The shape of the profile was progressive between the length of the microstructured die. Then, the structured blade passed onto a second tool called the "sizer". The sizer allowed the transition between the viscoelastic and solid states of the extrudate, which was then calibrated to the required dimensions. The sizer was equipped with a cooling circuit and an air circuit to generate vacuum inside the tooling. The vacuum promoted calibration by pressing the composite against the sidewalls. The blade completely cooled in a bath containing water. A dryer tool was positioned at the outlet of the cooling bath. The dry microstructured thin blade component having the correct by the puller at the end of the
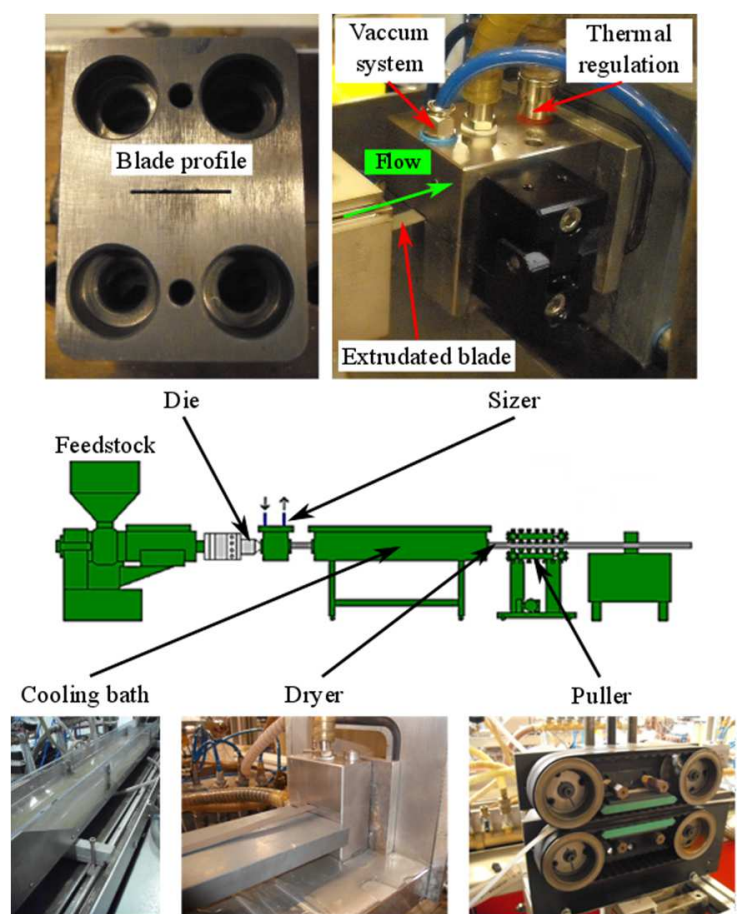

dimensions was extracted extrusion line. 
Fig. 4. Image of the extrusion line used for a microstructured thin blade. Schematic of the extrusion-forming tools: microstructured die, sizer, cooling bath, and dryer

\section{Experimental results and discussion}

\subsection{Preliminary rheological analysis and associated mixing tests}

Rheological tests were performed on the composite mixtures prepared by a mixing process. Twin-screw mixing process is the best compounding method, as it leads to the highest-quality products. The mixer employed contained a mixing chamber of volume $50 \mathrm{~cm}^{3}$ which included two Z-blade screws. The powders were loaded when the mixing chamber stabilised at the required mixing temperature. Two formulations of the composite (F1 and F2) were investigated by using the magnetocaloric powder A. The formulations F1 and F2 were elaborated based on PP and LDPE, respectively, as the polymer binders. The same magnetocaloric powder loading of 65 vol.\% was imposed for each of the formulations F1 and F2. The mixing temperature depended on the polymer grade. The formulations F1 and F2 were obtained at 180 and $140{ }^{\circ} \mathrm{C}$, respectively. The mixing process was repeated five times under the same processing parameters, 65 min mixing time, a rotation speed of $50 \mathrm{rpm}$, and a mixing temperature associated with the F1 or F2 formulation, to ensure homogeneity of the powder mixture. This mixing procedure and the screw speed were set at $50 \mathrm{rpm}$, which had been used in our previous works to elaborate homogeneous composites. The methodologies were recently described by Claudel et al. (2017).

One of the most important properties of a composite is its homogeneity. In twin-screw mixing process, when the torque reaches a steady-state value, it is assumed that a homogeneous mixture is formed, as described in detail by Thiébaud et al. (2010) for other related materials. During processing, the mixing-related torque is caused by the resistance of the sample composite to the shearing on the rotor blades. The mixing torque curves as function of time for both the formulations of the feedstock are shown in Fig. 5(a). The results suggest that homogeneous mixing, corresponding to the stability of the torque, is realised after $60 \mathrm{~min}$ and corresponds to uniform dispersion of the powder within the binder. For the composite formulations F1 and F2, the final mixing torques reached $10 \pm 0.02$ and $25 \pm 0.05 \mathrm{Nm}$, respectively. For the full range of mixing torque values, the accuracy of the final mixing torque is $0.2 \%$. At their respective mixing temperatures, the mixing torque of the composite F2 (LDPE) was higher than that of the composite F1 (PP). In the two cases, the final mixing torques were higher than $10 \pm 0.02 \mathrm{Nm}$, which suggested the formation of some highly viscous flow mixtures corresponding to extrusion processing behaviour (compounding and shaping). In conclusion, the feasibility of using feedstock during the extrusion processes was demonstrated by mixing and torque behaviour analyses.

The purpose of this investigation is to characterise the rheological behaviour in support of the shaping process performed on the custom-made magnetocaloric composite. The analyses were carried out by using a twin-bore capillary 
rheometer $250 \mathrm{~mm}$ in length and a barrel $15 \mathrm{~mm}$ in diameter. The composite was extruded through several tungsten carbide dies with lengths of 16 and $32 \mathrm{~mm}$ and diameters of 1 and $2 \mathrm{~mm}$. Other zero-length dies were used so that the Bagley correction could be applied to the data for a physical length of $0.2 \mathrm{~mm}$. Under conditions of steady flow and from measurements of the volumetric flow rate and the pressure drop through the rheometer, the shear viscosity can be determined as the ratio of the shear stress to the shear rate. To determine the true viscosity, procedural corrections, namely, the Bagley and Weissenberg-Rabinowitsch corrections, and rheological methodologies were employed, which are the same as those described by Claudel et al. (2017). Rheological analysis of the data was performed with the Rosand Flowmaster software. Rheometer tests for all the elaborated composites were conducted to obtain the steadystate shear flows at different shear rates ranging from $10^{2}$ to $10^{3} \mathrm{~s}^{-1}$, which correspond to the extrusion process parameters under different applied temperatures, to investigate the influence of shear rate on shear viscosity. The tests were carried out at 160,180 , and $200{ }^{\circ} \mathrm{C}$ on the elaborated composites for formulation $\mathrm{F} 1$ and at 120,140 , and $160{ }^{\circ} \mathrm{C}$ for formulation F2; the temperatures were higher than the melting points of the polymers (PP and LDPE). To ensure reproducibility of the rheological analysis data, each measurement was repeated five times, and the shear viscosity variations are less than $0.3 \%$. To further analyse the rheological data, the graphs of shear viscosity versus temperature and shear rate for the two composites were converted to log viscosity versus log shear rate plots, as shown in Fig. 5 (b). These graphs reveal that the viscosity decreased with increasing temperature and shear rate. The several composite flow curves, associated with F1 and F2, correspond to pseudoplastic behaviour of the magnetocaloric composite. Such a relation between temperature and the shear viscosity indicates that a low temperature improves the high viscosity of the composite through the die during the extrusion-based polymer processing. The loading of the magnetocaloric powder into the thermoplastic matrix composite modifies the shear viscosity, which increases significantly with respect to that of the pure polymer and increases more gradually with the increase in the powder loading by volume. Using fiberreinforced LDPE composite, the same conclusions were reached by Kalaprasad et al. (2003). The composite of formulation F1 exhibited a low shear viscosity, compared with that of formulation F2. This trend was also observed during the mixing tests, where the final mixing torque of composite F1 was lower than that of composite F2, as shown in Fig. 5(a). This confirms the existence of a relationship between the mixing torque and the shear viscosity of the magnetocaloric composite. In conclusion, the viscosity values of the two formulations were higher than $100 \mathrm{~Pa} \cdot \mathrm{s}$, which revealed that this value is useful to ensure sufficient rigidity at low temperatures and display optimal behaviour for extrusion processes. Bangarusampath et al. (2009) obtained the same result by using PEEK/MWNT composites. 

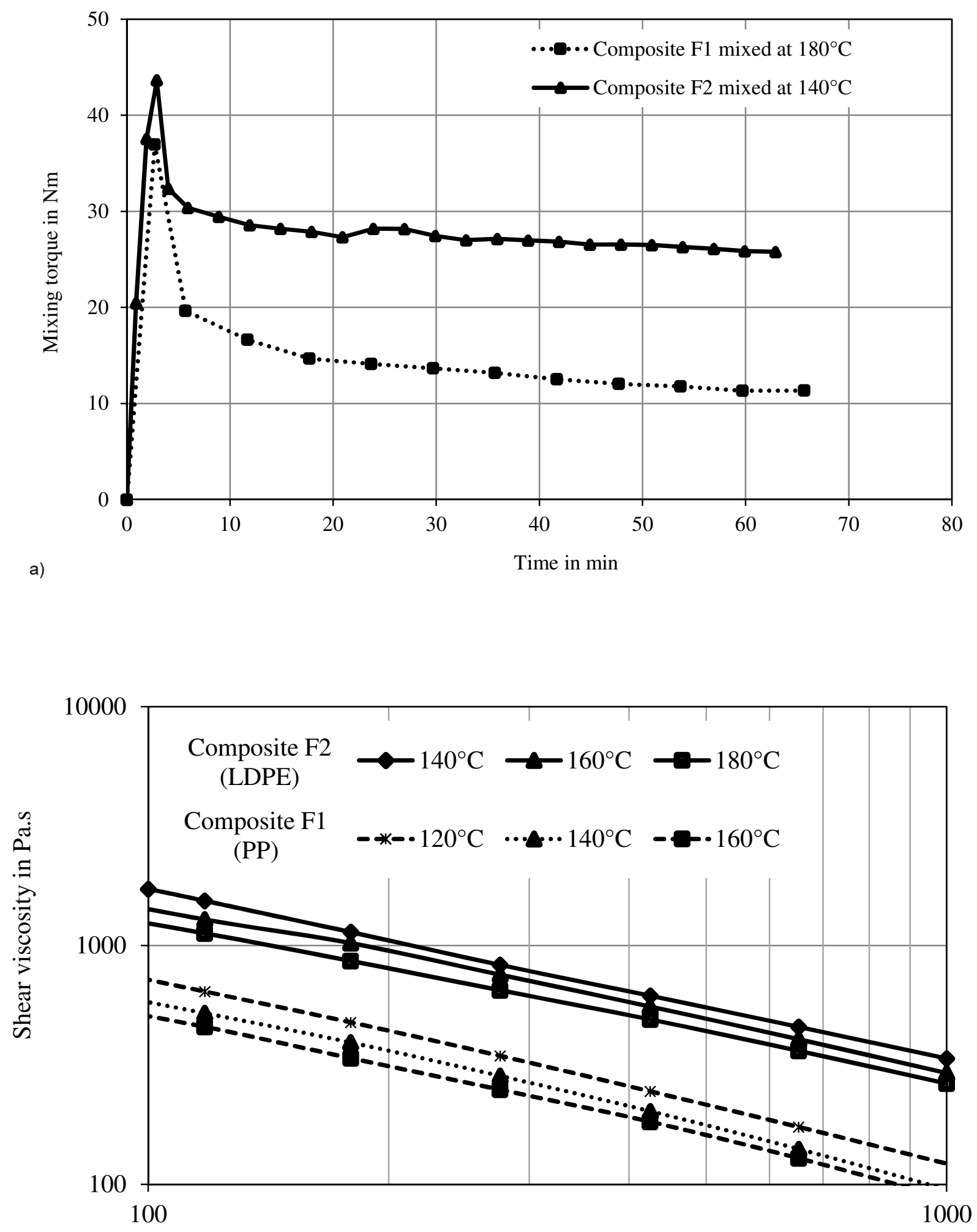

b)

Shear rate in /s

Fig. 5. (a) Evolution of mixing torque with time for F1 and F2 composite mixtures with 65 vol.\% magnetocaloric powder loading (mixing temperatures: $180{ }^{\circ} \mathrm{C}$ (F1) and $140{ }^{\circ} \mathrm{C}$ (F2), screw speed: $50 \mathrm{rpm}$ ); (b) evolution of shear rate viscosity flow curves with the shear rate and temperature of the two elaborated composites F1 and F2 


\subsection{Magnetocaloric feedstock elaboration}

The experiment started with the screw speed, feed rate, and barrel temperature profile of $100 \mathrm{rpm}, 2 \mathrm{~kg} / \mathrm{h}$, and $150-170$ ${ }^{\circ} \mathrm{C}$, respectively. Because of this temperature profile, the $\mathrm{T}_{\mathrm{c}}$ was not modified. Indeed, dehydrogenation phenomenon was observed, with an elaboration temperature of approximately $200{ }^{\circ} \mathrm{C}$. Before the extrusion test, the polymer was placed in a heating and drying oven at approximately $70{ }^{\circ} \mathrm{C}$ for $6 \mathrm{~h}$ to eliminate residual humidity. The processing parameters used for the composite formulations F1 and F2 during the extrusion tests are listed in Table 1.

The investigation was carried out on the formulation F2 of powders A2 and LDPE. The optimal powder loading was obtained as $60 \mathrm{vol} . \%$. The procedure made it possible to achieve stability of the pressure and torque, as observed in Fig. 6. The variation in the powder loading from 41 to 60 vol. $\%$ was needed to increase the extrusion temperature from 150 170 to $160-170{ }^{\circ} \mathrm{C}$. This increase reduced the relative shear viscosity of the composite, which in turn decreased the torque value. On the other hand, the increase in the powder loading by volume resulted in increases in the pressure and torque values. Peaks of the pressure and torque were also observed, as noticed in Fig. 6, within the experimental standard error ranges. The final values of the pressure and torque varied from $2.0 \pm 0.02 \mathrm{MPa}$ and $80 \pm 0.16 \mathrm{Nm}$ for 41 vol. $\%$ of powder to $4.0 \pm 0.02 \mathrm{MPa}$ and $89 \pm 0.18 \mathrm{Nm}$ for 60 vol. $\%$ powder. Sedlacek et al. (2004) previously revealed the same extrusion behaviour for other related materials. The increase in the pressure implied a continuous increase in the shear viscosity, which is similar to the observations made in capillary rheology.

Comparative processing tests show that the maximal powder loading by volume determined by twin-screw extrusion was lower than that obtained with a twin-screw mixer, as observed in Figure 5 (a) and Figure 6. The optimal powder loading, estimated at 65 vol.\% in the mixer, decreased to 60 vol.\% in the extruder. It was obtained with the optimal extrusion parameters: a mixing temperature profile of $160-170{ }^{\circ} \mathrm{C}$ and a screw speed of $200 \mathrm{rpm}$. Therefore, the values of pressure and torque were below the limits of the extruder. The mixing temperature was below the limit of use of the magnetocaloric powder, equal to $200{ }^{\circ} \mathrm{C}$, which corresponded to the degradation temperature. Two lots of magnetocaloric composites were prepared with powder loadings of 41 and $60 \mathrm{vol} . \%$. 


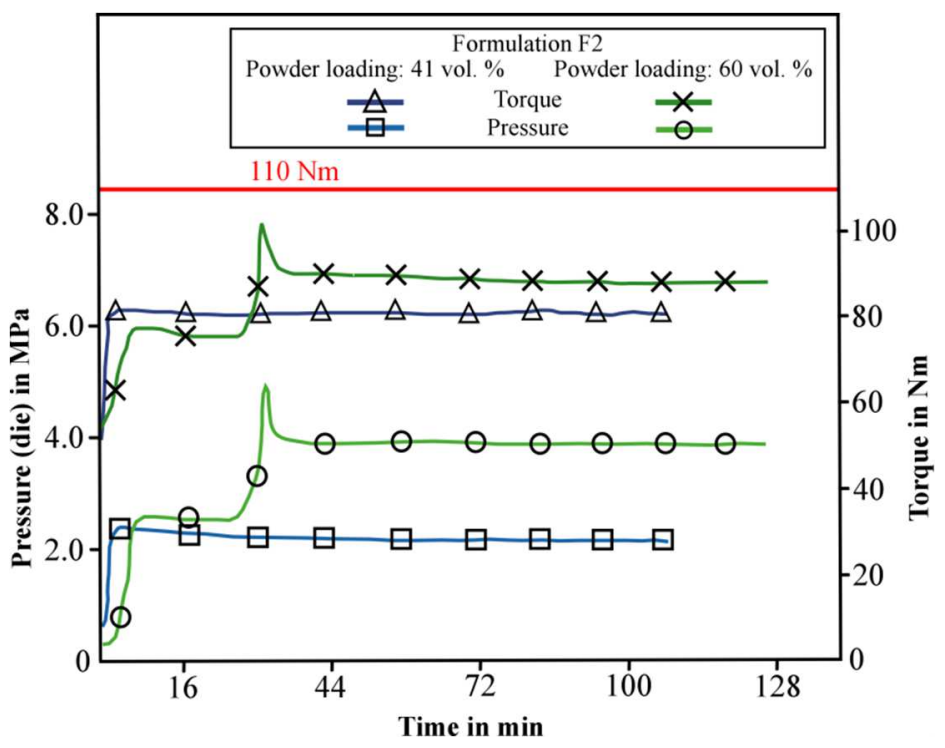

Fig. 6. Pressure and screw torque curves vs. time for formulation F2 with powder loadings of 41 (blue) and 60 vol. \% (green)

In the case of the composite formulation F1 (powder A1 and PP), the extrusion tests were stopped for the powder loading of $62 \mathrm{vol} \% \%$ because of unstable process. The torque limit was reached with the temperature profile of the barrel being $190-200{ }^{\circ} \mathrm{C}$ (Table 1). The powder loading was reduced to 53 vol.\% to realise stability. The temperature profile was also between 185 and $190{ }^{\circ} \mathrm{C}$. This temperature range corresponded to the uncertainty zone of the hydrogenated magnetocaloric powders. The $\mathrm{T}_{\mathrm{c}}$ was controlled by performing DSC on the composites elaborated. At the end of the extrusion tests, one lot of the magnetocaloric composite (F1) was produced with a powder loading of 53 vol.\%.

Table 1. Optimal extrusion setting parameters for composite elaboration and the screw torque, and the associated pressure results

\begin{tabular}{|c|c|c|c|c|}
\hline $\begin{array}{c}\text { Formulation (magnetocaloric } \\
\text { powder + binder) }\end{array}$ & $\begin{array}{c}\text { Powder loading rate } \\
(\mathbf{v o l .} \%)\end{array}$ & $\begin{array}{c}\text { Die/barrel temperature } \\
\left({ }^{\circ} \mathbf{C}\right)\end{array}$ & $\begin{array}{c}\text { Screw torque } \\
(\mathbf{N m})\end{array}$ & $\begin{array}{c}\text { Pressure } \\
(\mathbf{M P a})\end{array}$ \\
\hline F1 (A1+PP) & 53 & $180 / 185-190$ & $70 \pm 0.14$ & $2.0 \pm 0.02$ \\
\hline F1 (A1+PP) & 62 & $185 / 190-200$ & $/$ & $/$ \\
\hline F2 (A2+LDPE) & 41 & $150 / 150-170$ & $80 \pm 0.16$ & $2.7 \pm 0.02$ \\
\hline F2 (A2+LDPE) & 60 & $160 / 160-170$ & $89 \pm 0.18$ & $4.0 \pm 0.02$ \\
\hline
\end{tabular}

\subsection{Shaping by extrusion process}

Two formulations of magnetocaloric composites developed by the innovative and complex extrusion-forming line tools were investigated for structured thin-blade-shaped specimens for the processing parameters listed in Table 2 : formulation F1 with a powder loading of $53 \%$ of the A1 powder, and formulation F2 with 60 vol. $\%$ loading of A2 powder. Optimization of the extrusion parameters made it possible to stabilise the process of production of thin blades after $30 \mathrm{~min}$ without interruption. Some dimensional measurements were carried out on the extruded blades. They showed thinning of the blades at the ends, which indicated a lack of material in the inlet of the sizer. The geometry of the die profile was modified to rectify this. It was expanded to allow filling of the sizer. New shaping tests were carried 
out with this modified extrusion tool. The dimensional measurements performed on the thin blades at the beginning of the process showed that the material deficiency was finally corrected. In comparison, the composite formulation F2 exhibited better behaviour during the shaping phase than the formulation F1. In fact, it was more viscous than composite F1 with the same extrusion temperature but corresponding to a higher powder loading rate. This behaviour facilitated the start-up and stabilisation of the thin blade process. At the end of the shaping tests of the magnetocaloric composite, $250 \mathrm{~m}$ of thin plates were produced at a rate of $4 \mathrm{~m} / \mathrm{min}$. The development of the extrusion line and the tests carried out showed the industrial potential for producing magnetocaloric components.

The composite resulting from the formulation F2 exhibited better extrusion behaviour for the shaping chosen for the metrological analysis. Thickness measurements were carried out by using a digital micrometre on the two batches of thin blades produced before and after the modification of the profile die. A structured blade sample was taken for both the batches after cooling every $10 \mathrm{~cm}$ by $4 \mathrm{~m}$ of the extruded blade. Each sample was divided into five measurement areas $(\mathrm{A}, \mathrm{B}, \mathrm{C}, \mathrm{D}$, and $\mathrm{E})$. The main results of the thickness measurements of the structured blade are summarised in Fig. 7 a) and b). Two thickness reductions were observed at the two ends of the blade (measuring points A and E) relative to the central point C, see Fig. 7 (a). Moreover, the averages of the measured thicknesses were far from the target dimensions; nevertheless, they were within the tolerance range. Only the thickness measurements taken at the two ends of the blade were out of tolerance. A geometric modification of the design of the profile die was carried out to obtain thin blades conforming to the dimensional specifications. The new metrological analysis was performed with the aim of highlighting the dispersions in the thickness measurements to validate the modifications. The extruded thin blades were in conformity with the geometrical tolerance, see Fig. 7 (b). Indeed, the average values were close to the target thickness. The maximum and minimum values were within the tolerance range, and the thickness was homogeneous over the entire structured blade section, as seen in Fig. 7 (b). From a statistical analysis, the mean of the standard deviations of each of the two batches of thin blades was approximately $0.004 \mathrm{~mm}$. The low standard deviation values validate the developed procedure and indicate that the thickness measurements were not dispersed from the mean. In conclusion, the level of dimensional accuracy achieved through the extrusion process is satisfactory for highly loaded composites and thin structured components. The extrusion tool line developed demonstrated its ability to produce magnetocaloric components with the required geometric tolerances.

Table 2. Optimal extrusion settings for composite blade elaboration

\begin{tabular}{|c|c|c|c|c|c|c|c|}
\hline \multirow{2}{*}{ Formulation } & \multirow{2}{*}{$\begin{array}{l}\text { Screw speed } \\
(\mathrm{rpm})\end{array}$} & \multicolumn{5}{|c|}{ Mixing temperature $\left({ }^{\circ} \mathrm{C}\right)$} & \multirow[t]{2}{*}{ Sizer temperature $\left({ }^{\circ} \mathrm{C}\right)$} \\
\hline & & & & Mic & oint & Die & \\
\hline F1 & 15 & 155 & 155 & 155 & 160 & 160 & 80 \\
\hline
\end{tabular}




\begin{tabular}{|l|l|l|l|l|l|l|l|}
\hline F2 & 15 & 155 & 155 & 155 & 160 & 160 & 80 \\
\hline
\end{tabular}
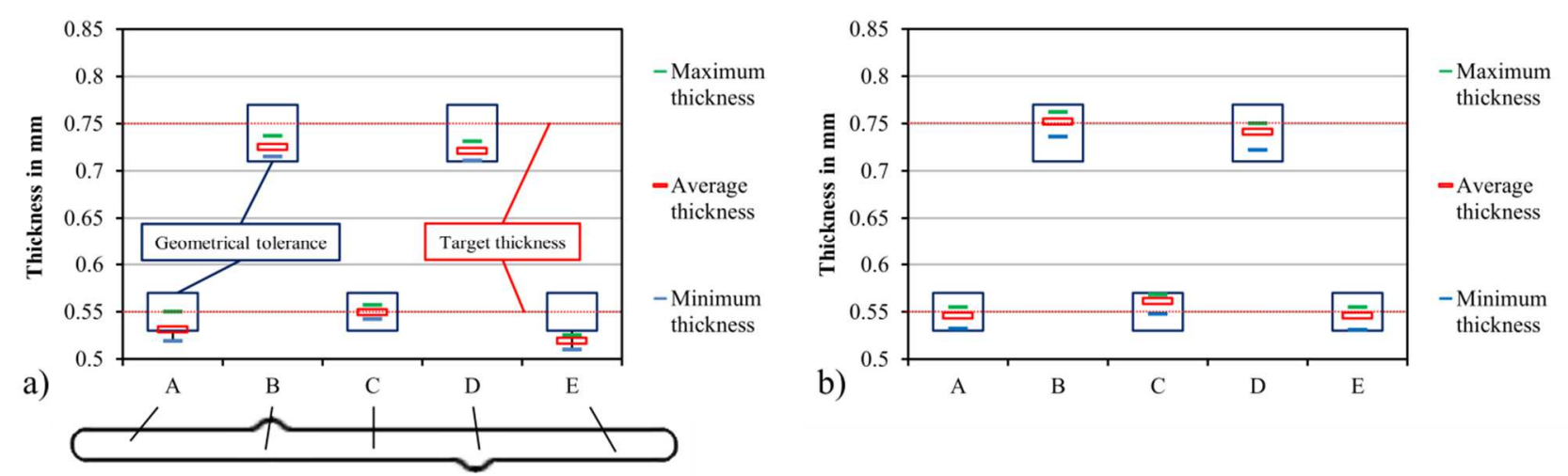

Fig. 7. Evolution of the blade thickness for the positions A, B, C, D, and E: a) initial shape of the design die, b) with the modified and optimal die

\section{Thermophysical analysis of the extruded components}

Characterisation of the magnetocaloric components is an important aspect of the validation of the extrusion process. The goal is to control the stability of the magnetocaloric properties during the elaboration process of the blades. Control of the functional magnetocaloric properties such as the $T_{c}$ and MCE is necessary to analyse and quantify the component performances in magnetic refrigeration. Tishin et al. (2003) largely studied the MCE and its applications. Such characteristics were also analysed by Gómez et al. (2013). The MCE is manifested by a temperature variation $\Delta \mathrm{T}$ under an imposed magnetic field. It is reversible and maximal around the critical order-disorder temperature, $\mathrm{T}_{\mathrm{c}}$. In the medium term, the magnetocaloric components are integrated in a refrigeration device of the AMR type. Indeed, these regenerators use successive $\mathrm{Tc}$ components $\left(\mathrm{T}_{\mathrm{ci}}, \mathrm{Tc}_{1}, \mathrm{Tc}_{2}, \ldots, \mathrm{T}_{\mathrm{cf}}\right.$ ), which have been described by Jacobs et al. (2014).

Maintaining the measurement accuracy of the $T_{c}$ is essential throughout the component fabrication process. The $T_{c}$ was determined by DSC. Another key aspect of the magnetocaloric component is its performance during the AMR cycle. This performance is reflected in the adiabatic temperature variation $(\Delta \mathrm{T})$ under a magnetic field. $\Delta \mathrm{T}$ is maximal in the case of pure powders. Pulko et al. (2015) quantified the AMR of epoxy-bonded composite plates which was built and experimentally tested. Finally, the dilution effect of the powders in the thermoplastic matrix decreases the initial $\Delta \mathrm{T}$. For a given volume $V$, the MCE is maximal around the Tc in the case where the volume of magnetocaloric powders $V$ powder corresponds to $V$. Then, the presence of the thermoplastic matrix decreases the volume fraction occupied by the powder for the same $V$ ( $V=V_{\text {binder }}+V_{\text {powder }}$ ). The $V$ of active magnetocaloric powders in terms of MCE will, therefore, be less, which explains the decrease in the performance of the final feedstock. The development of the formulations and the process of developing the composite must make it possible to achieve high and constant loading rates. TGA and He 
pycnometer density measurements of mixtures and thin sections make it possible to check the homogeneity and control the powder loading rate throughout the production process.

\subsection{Quantification of the $T_{c}$}

The Tc of the magnetocaloric powders studied were adjusted based on the proportion of $\mathrm{H}$ inserted at the time of hydrogenation of the powders during the powder production process, as reported by Mayer et al. (2014). They investigated the influence of processing temperature on the stability of the Tc value, and their results show a shift in the peak of the Tc toward lower temperatures. The degradation of the magnetocaloric powder matrix, which is partially dehydrogenated, in polymer processing during the elaboration of the composites by the mixing process leads to undesirable heating to a high temperature. This phenomenon was observed for the composite elaborated at $200{ }^{\circ} \mathrm{C}$ in the twin-screw mixer.

The first limit to using these hydrogenated powder alloys was reached. The reference Tc of the powders and the elaborated composites were determined by DSC analysis. The tests were carried out at a heating rate of $10{ }^{\circ} \mathrm{C} / \mathrm{min}$ from -60 to $40{ }^{\circ} \mathrm{C}$ for powder $\mathrm{A} 1$ and 0 to $50{ }^{\circ} \mathrm{C}$ for powder $\mathrm{A} 2$. The composites and the structured blade were elaborated with the polymer and/or forming extrusion processes corresponding to the formulations F1 and F2.

The reference Tc of the powders A1 and A2 were $-21 \pm 2$ and $23.5 \pm 2{ }^{\circ} \mathrm{C}$, respectively. Fig. 8 presents the DSC powder thermograms of the two-screw extrusion composite mixtures and thin-section samples. Fig. 8 (b) shows that the Tc was not modified.

Indeed, no shift in the Tc relative to the reference value was observed. The temperature profiles used successively for F2 (Tables 1 and 2) make it possible to preserve the Tc throughout the process of elaboration of the thin sections. In the case of F1, the extrusion temperature profile of $180-190{ }^{\circ} \mathrm{C}$ caused a shift in the Tc, as shown in Fig. 8 (a). The peaks of the Tc of the elaborate composite and the extruded thin strip shifted by $2.5 \pm 2{ }^{\circ} \mathrm{C}$ toward lower temperatures, relative to that of the magnetocaloric powder. The magnetocaloric powders contained in the composite were partially dehydrogenated. The sensitivity of the use temperature was demonstrated, with the integrity of the magnetocaloric properties being threatened for temperature profiles higher than $185-190{ }^{\circ} \mathrm{C}$.

Some representative sampling composites and blades were selected with different binder formulations and for different processing parameters during the polymer extrusion and forming processes to evaluate the physical functional properties.

The $\mathrm{T}_{\mathrm{c}}$ of the powders $\mathrm{A} 1$ and $\mathrm{A} 2$ are $-21 \pm 2$ and $23.5 \pm 2{ }^{\circ} \mathrm{C}$, respectively, as revealed in Fig. 8. The DSC thermograms of the powders, elaborated composite, and final structured blades have been plotted against temperature in Fig. 8 (a) for F1 and Fig. 8 (b) for F2. In F2, with respect to the processing parameters listed in Tables 1 and 2 , the $\mathrm{T}_{\mathrm{c}}$ was more stable from the powder stage to the final mixing and shaping processes and its value was $23.5 \pm 2{ }^{\circ} \mathrm{C}$. This 
was the opposite of $\mathrm{F} 1$ formulation, in which the $\mathrm{T}_{\mathrm{c}}$ showed a slight variation during the proposed process from the powder form to the final parts. By taking into account the $\mathrm{T}_{\mathrm{c}}$ of $\mathrm{A} 1$ as a reference, a decrease of $2.5 \pm 2{ }^{\circ} \mathrm{C}$ towards lower temperatures was observed which indicated a partially dehydrogenated final blade (see Fig. 8). This defect was produced at a high forming-extrusion temperature of $185-190{ }^{\circ} \mathrm{C}$.

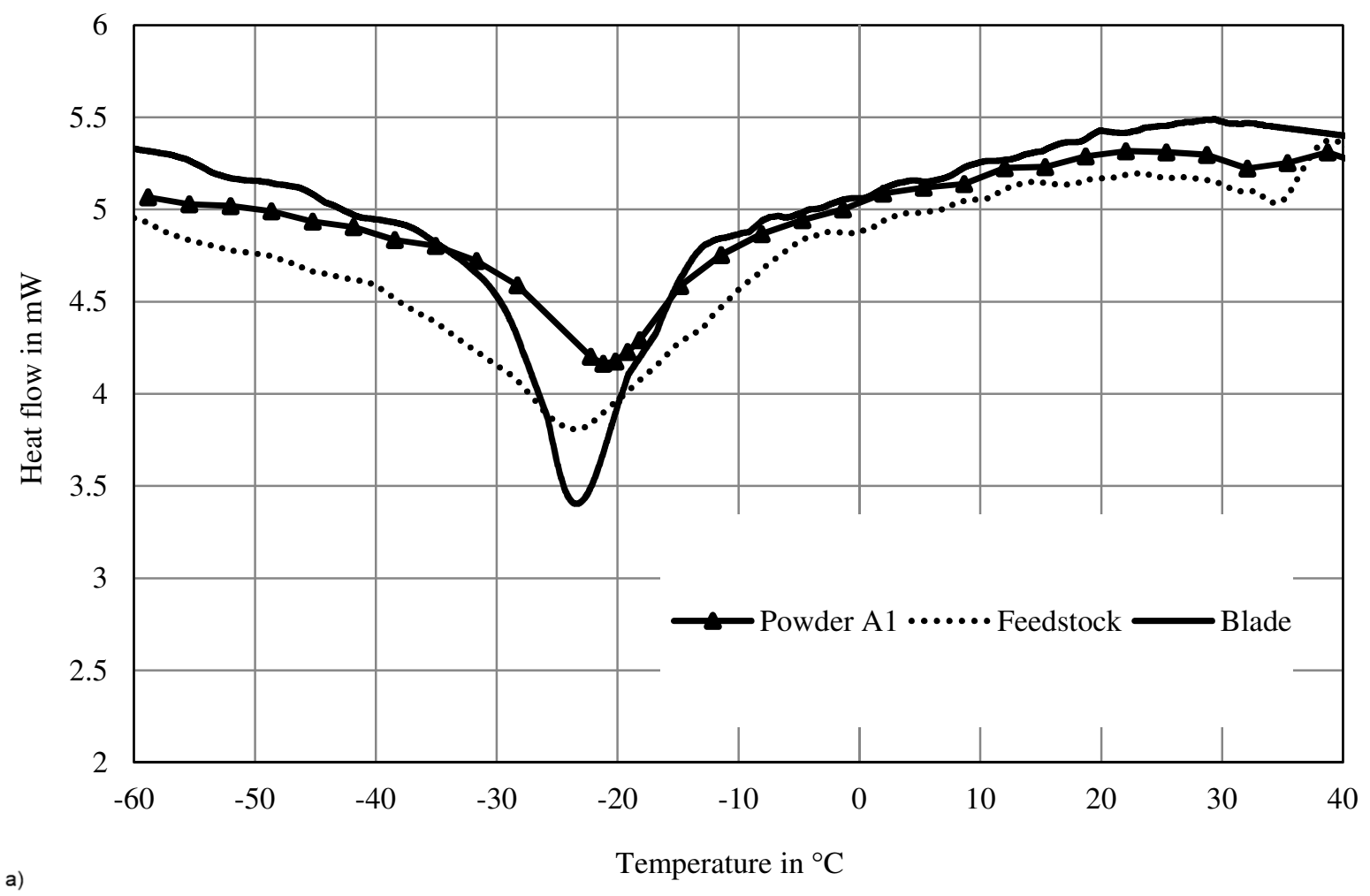




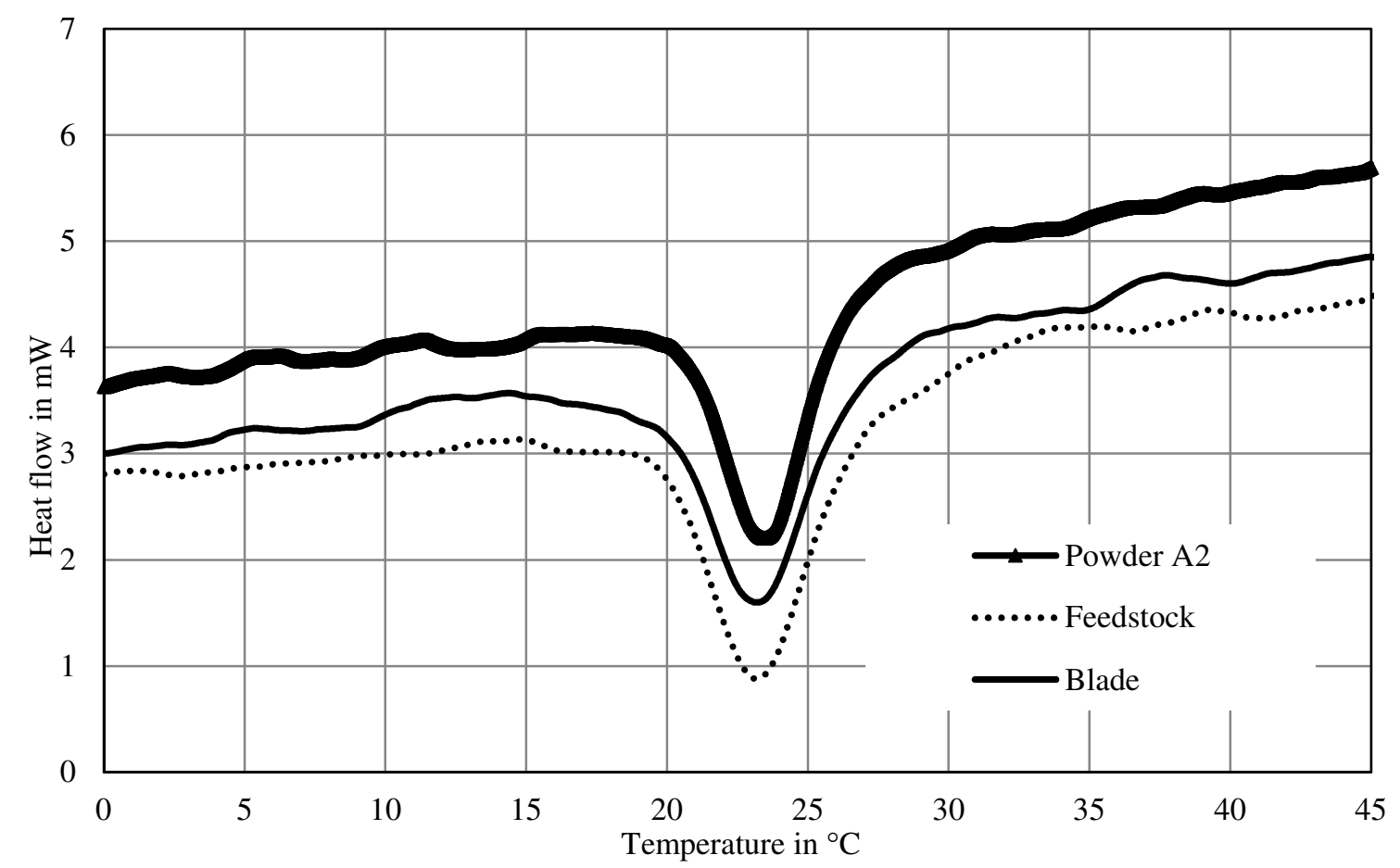

b)

Fig. 8. Control of the Tc by DSC analysis at different steps of the process from the powder form to the composite elaboration and final shaping processes: a) formulation $F 1$, b) formulation $F 2$

\subsection{Analyses of the composites}

The densities of the composite materials can be used to quantify the homogeneities of the elaborated composites and structured blades. The densities were measured with a He pycnometer. A large difference in the density was observed between the magnetocaloric powders and the binder, the densities of which equalled 7.3 and $0.9 \mathrm{~kg} / \mathrm{cm}^{3}$, respectively. A small variation in the powder loading caused by unadapted process parameters or a poor tooling line during the extrusion and forming processes generated a large density difference in the polymer composite materials. This difference directly affected the MCE. The theoretical density was determined according to equation (1) based on the mixture law proposed by Demers et al. (2015):

$\rho_{\text {composite }}=$ vol. $\%_{\text {powder }} \cdot \rho_{\text {powder }}+\operatorname{vol.} \%_{\text {binder }} \cdot \rho_{\text {binder }}$

The results of the density measurements and the associated mean values of the elaborated composites and structured blades are given in Table 3. The average densities of the elaborated composite and structured blade were $4.667 \pm 0.006$ and $4.669 \pm 0.004 \mathrm{~g} / \mathrm{cm}^{3}$, respectively. The maximal density was less than $0.3 \%$ (see Table 3 ). By application of the previous relation, the theoretical $\rho_{\text {composite }}$ was $4.748 \mathrm{~g} / \mathrm{cm}^{3}$ for F2, which corresponded to $60 \%$ powder loading. The value of $4.669 \mathrm{~g} / \mathrm{cm}^{3}$ corresponded to $58.8 \%$ powder loading. Comparison of the experimental and theoretical density values indicated an error of $1.7 \%$. The densities of the elaborated composites and structured blades during the 
continuous extrusion and forming processes were the same as the theoretical values, except for a small standard deviation. These values indicate a homogeneously elaborated composite with stable process and optimal parameters without any extrusion defects. The conclusion is the same for the final blade obtained with a high powder loading of approximately $60 \%$ by volume and without any external defects.

Table 3. Results of density measurements of the elaborated composites and structured composite blades

\begin{tabular}{|c|c|c|c|c|c|c|c|c|}
\hline \multirow[b]{2}{*}{ Sample } & \multicolumn{4}{|c|}{ Elaborated composite } & \multicolumn{4}{|c|}{ Structured blade } \\
\hline & 1 & 2 & 3 & 4 & 1 & 2 & 3 & 4 \\
\hline Density $\left(\mathrm{g} / \mathrm{cm}^{3}\right)$ & 4.675 & 4.662 & 4.662 & 4.668 & 4.664 & 4.669 & 4.673 & 4.669 \\
\hline Average value $\left(\mathrm{g} / \mathrm{cm}^{3}\right)$ & \multicolumn{4}{|c|}{$4.667 \pm 0.006$} & \multicolumn{4}{|c|}{$4.669 \pm 0.004$} \\
\hline
\end{tabular}

The homogeneity of the composite material formed was quantified by thermal analyses of the different structured blades. In nitrogen atmosphere, the TGA patterns were obtained from room temperature to $500{ }^{\circ} \mathrm{C}$ at the same heating and cooling rate $\left(2{ }^{\circ} \mathrm{C} / \mathrm{min}\right)$. The experiments were repeated five times to confirm the repeatability of the experimental data. The method of sample selection was as follows: three structured blade samples were considered every $1 \mathrm{~m}$ of the continuous extrusion blade, which were named zones 1, 2, and 3, and, for each location, three different samples were considered for TGA (point $\mathrm{A}$ at the first side, $\mathrm{C}$ at the middle part and $\mathrm{D}$ at the second side; all the points are defined in Fig. 7). The TGA curves of the composite and blade were compared to validate the homogeneity and powder volume fraction during the extrusion and forming processes (Fig. 9 (a)). For each location and sample, the same evolutions were obtained during the analyses, with a maximal discrepancy of $0.3 \%$ (Table 4 and Fig. 9 (b)). During the TGA, the maximal weight loss of the binder was $7.4 \%$, which corresponded to a solid volume fraction of $60 \%$ at the maximal temperature of $500{ }^{\circ} \mathrm{C}$. The homogeneities of the highly loaded magnetocaloric composite and the structured blade were demonstrated, which validated the entire experimental setup and the associated procedures. The next step was to test the functional magnetocaloric properties associated with this composite and blade components for a $\mathrm{La}(\mathrm{Fe}, \mathrm{Si})_{13} \mathrm{powder}$ loading of 60 vol.\% (or $~ 93 \%$ powder content by weight). 

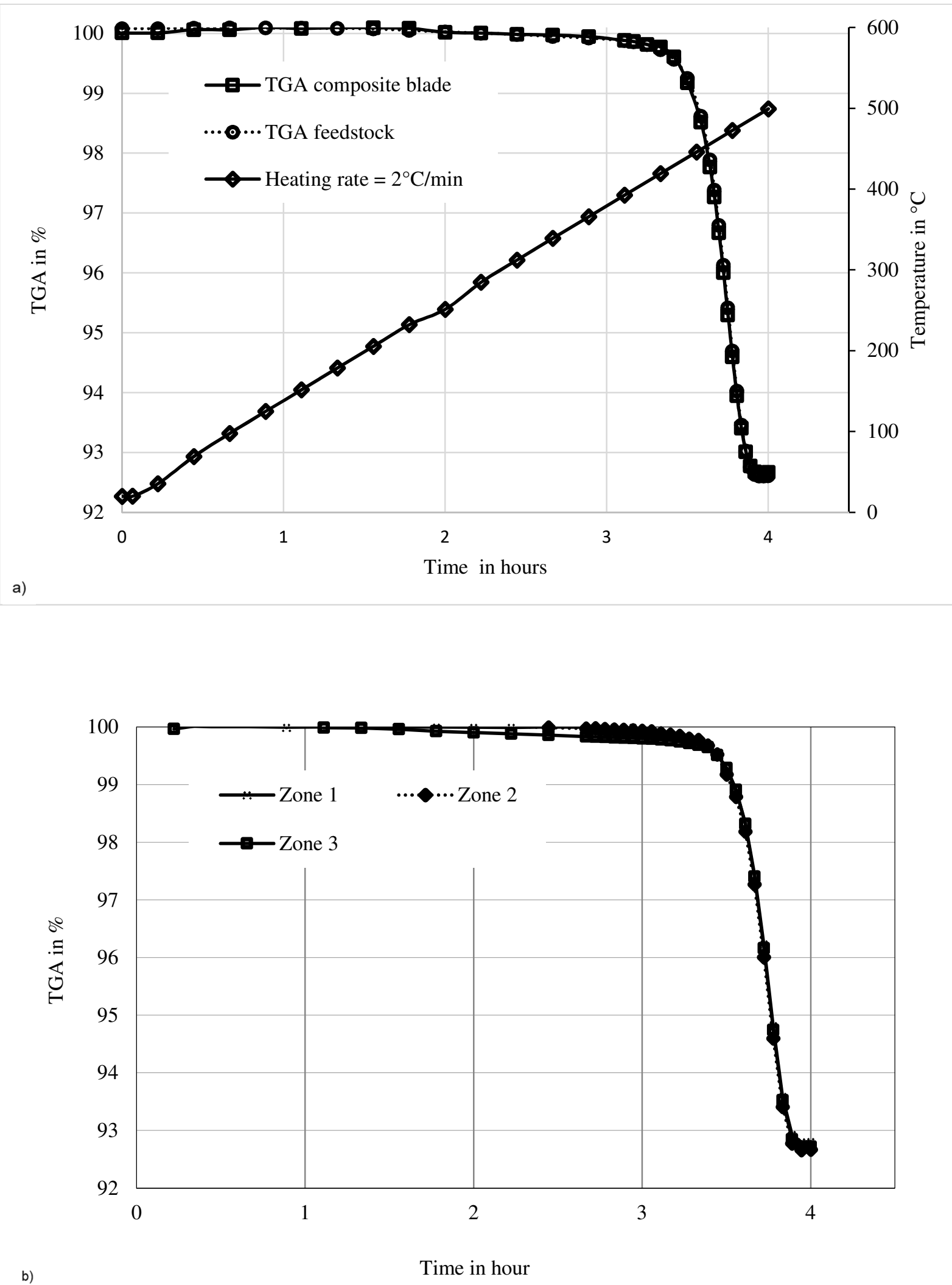

Fig. 9 (a) Remaining polymer content versus time of the elaborated composite and structured blade, (b) remaining polymer content versus temperature of the blade at different zones 
Table 4. Results of weight loss comparison

\begin{tabular}{|c|c|c|c|c|}
\hline & \multicolumn{3}{|c|}{ Weight loss $(\%) \pm 0.05 \%$} & \multirow{2}{*}{ Average weight loss in the zone $(\%)$} \\
\hline & Position 1 & Position 2 & Position 3 & $7.32 \pm 0.06$ \\
\hline Zone 1 & 7.25 & 7.35 & 7.35 & $7.44 \pm 0.06$ \\
\hline Zone 2 & 7.45 & 7.49 & 7.37 & $7.32 \pm 0.10$ \\
\hline Zone 3 & 7.41 & 7.34 & 7.21 & \\
\hline $\begin{array}{c}\text { Average weight loss for each } \\
\text { position (\%) }\end{array}$ & $7.37 \pm 0.11$ & $7.39 \pm 0.08$ & $7.31 \pm 0.09$ & \\
\hline
\end{tabular}

\subsection{Analysis of magnetocaloric effect}

The evolution of the variation in the adiabatic temperature $\left(\Delta \mathrm{T}_{\mathrm{ad}}\right)$ under an imposed magnetic field is one of the properties influencing the MCE of a magnetocaloric material. Some criteria were defined to quantify the efficiency of the magnetocaloric structured thin blades. These efficiency criteria based on $\Delta \mathrm{T}_{\text {ad }}$ (expressed in $\left.\%\right)$ were defined by the ratio of $\Delta \mathrm{T}_{\text {blade }}$ to $\Delta \mathrm{T}_{\text {powder }}$, which were measured for the (LDPE/La(Fe, Si) $\left.)_{13}\right)$ magnetocaloric structured blades and the $\mathrm{La}(\mathrm{Fe}, \mathrm{Si})_{13}$ powder. The two $\Delta \mathrm{T}$ terms were quantified by direct measurements under a magnetocaloric field of $1 \mathrm{Tesla}$ by using special equipment and the experimental procedure developed by Balli et al. (2009). The direct method offers the advantage of understanding the performance of a magnetocaloric material. The evolution of the efficiency criterion $\Delta \mathrm{T}_{\mathrm{ad}}$ with respect to powder loading is displayed in Fig. 10. The curve shows that the $\Delta \mathrm{T}_{\mathrm{ad}}$ increases linearly with the increase in the powder loading. The efficiency term varies from $81 \%$ to $92 \%$, corresponding to $38 \%$ and $51 \%$ powder loadings, respectively. During the extrusion and forming processes, it is necessary to use a thermoplastic binder in the magnetocaloric composite; consequently, the maximal efficiency obtained was $92 \%$. 


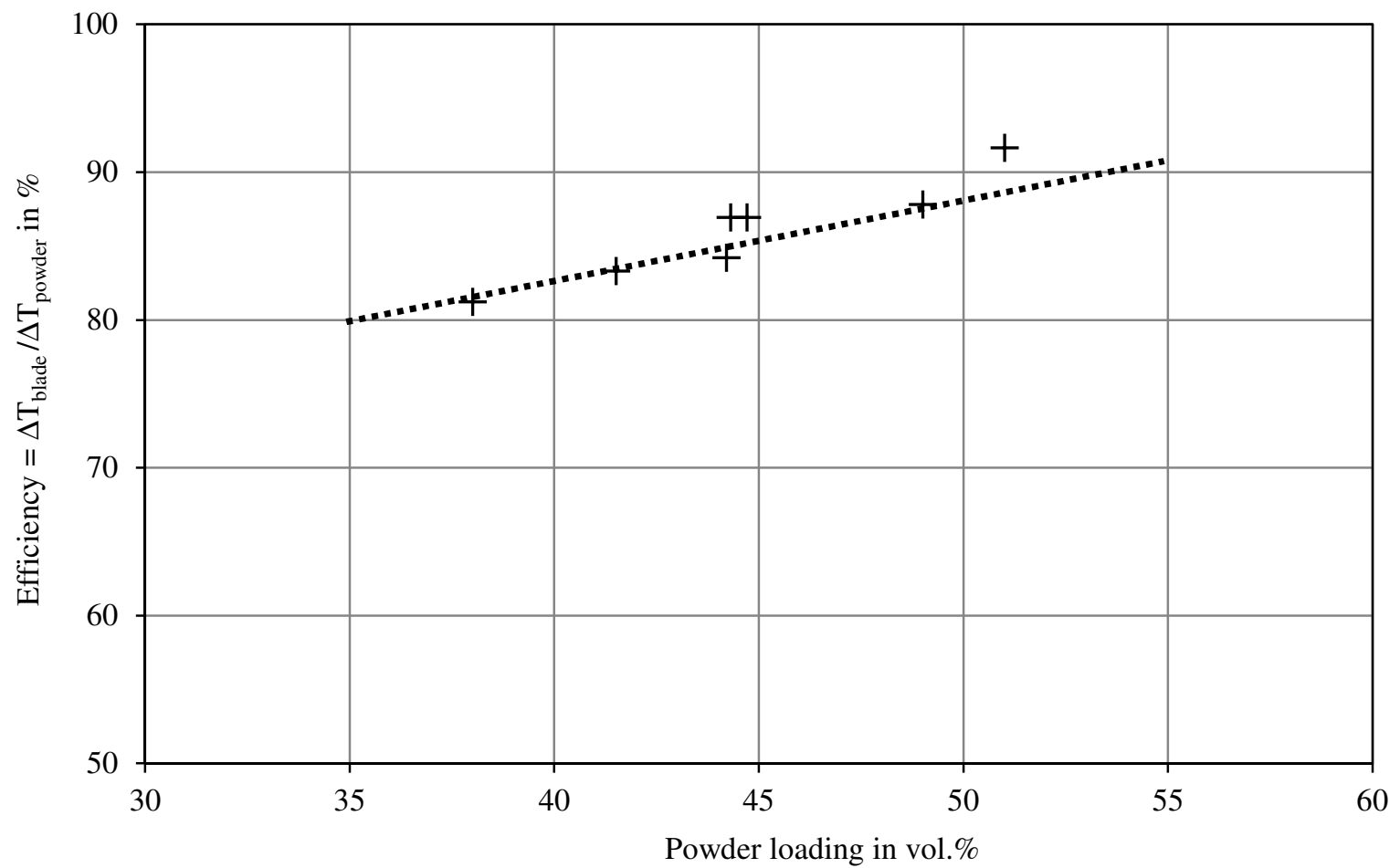

Fig. 10. Evolution of the efficiency of the thin and structured composite blade as a function of the powder loading rate

\section{Conclusion}

Innovative polymer extrusion and forming processes were investigated for the production of $2 \mathrm{D}$ composite structured parts based on $\mathrm{La}(\mathrm{Fe}, \mathrm{Si})_{13}$ alloys. Experimental studies were performed according to the shaping process for different thermoplastic polymer formulations and powder loadings. The composite materials along with their magnetocaloric properties were studied. Such structured magnetocaloric components were fabricated as regenerators or blade shapes with functional properties.

In the present work, the loadings chosen ranged from $35 \%$ to $65 \%$ by volume of $\mathrm{La}(\mathrm{Fe}, \mathrm{Si})_{13}$ alloys and the viscosity behaviours were investigated. As expected, incorporation of the powder in the thermoplastic polymer matrix modified the shear viscosity, which significantly increased with the $\mathrm{La}(\mathrm{Fe}, \mathrm{Si})_{13}$ powder loading. From the experiments carried out, the composite flow curves associated with F1 (PP/La(Fe, Si) $\left.{ }_{13}\right)$ and F2 (LDPE/La(Fe, Si) 13 indicated that the mixtures exhibit pseudoplastic behaviour. These composites reveal high shear viscosities which are suitable for polymer extrusion and forming processes. 
In the case of F2, the optimal powder loading based on the observed behaviour was considered to be 60 vol. $\%$, with a low imposed extrusion temperature of $160-170{ }^{\circ} \mathrm{C}$. At this temperature, the powder and the elaborated composites contained no dihydrogen. It is clear that the optimum powder loading is dependent on parameters such as shape, powder particle size, and thermoplastic formulation.

A specific and innovative forming tool was developed and optimised to obtain some components without defects through a stable and continuous process. The densities of the elaborated composite and final blade were the same, and corresponded to the theoretical values, which indicated a homogeneous elaborated composite, and the final blade was obtained without any extrusion defects via a stable process with optimal parameters.

The blades elaborated at high volumes with F2 composites and optimal specific tooling line configurations revealed no dihydrogen in the powders during the forming process, and the $T_{c}$ value measured was stable and exhibited the same sensitivity for the powders, composites, and structured blades, which was observed in the DSC rheogram.

The TGA curves of the composite and blade were compared to validate the homogeneity and powder volume fraction during the extrusion and forming processes. For each location and sample, the same binder evolutions were obtained with a maximal discrepancy of $0.3 \%$. The maximal weight loss of the binder was $7.4 \%$, which corresponded to a solid volume fraction of $60 \%$, and the homogeneities of the-composite and blade were revealed to validate the experimental setup and procedures.

After the tests on $\mathrm{La}(\mathrm{Fe}, \mathrm{Si})_{13}$ powder and $\left(\mathrm{LDPE} / \mathrm{La}(\mathrm{Fe}, \mathrm{Si})_{13}\right)$ extruded and formed structured blades, the $\Delta \mathrm{T}_{\mathrm{ad}}$ obtained increased linearly with the increase in the powder loading from $81 \%$ to $92 \%$ by weight, which corresponded to $38 \%$ and $51 \%$ powder loadings by volume, respectively. The maximal efficiency obtained was $92 \%$.

The shaping of the structured blades was studied by using a highly loaded $\mathrm{La}(\mathrm{Fe}, \mathrm{Si})_{13}$ powder polymer processed from the compounding to the forming process through the development of innovative processes and dedicated extrusion lines equipped with well-designed microstructured blade-forming tools. The $\mathrm{T}_{\mathrm{c}}$ was stable from the powder stage to the mixing process and final material shaping, and the (LDPE/La(Fe, Si) $\left.{ }_{13}\right)$ elaborated composite and structured blades were homogenous, with the maximal efficiency of $92 \%$.

Thin structured blades of thickness $0.5 \mathrm{~mm}$ were obtained with micropatterns of width $200 \mu \mathrm{m}$. The low standard deviation values validate the procedure and indicate that the thickness measurements are not dispersed from the mean. In conclusion, the level of dimensional accuracy achieved by using a thermoplastic polymer micro-extrusion and forming process from composite elaboration to final functional microstructured blades is excellent. The procedure will be improved in the future to fabricate magnetocaloric regenerators with more complex geometries by using smaller 
particle sizes to decrease the blade thickness. The associated microstructure and/or nanostructure surface can be used to produce efficient and more complex cooling systems. 


\section{References}

Akdogan, H.. 1996. "Pressure, Torque, and Energy Responses of a Twin-screw Extruder at High Moisture Contents." Food Research International 29 (5): 423-29.

Balli, M., D. Fruchart, O. Sari, D. Gignoux, J. H. Huang, J. Hu, and P. W. Egolf. 2009. "Direct Measurement of the Magnetocaloric Effect on $\mathrm{La}(\mathrm{Fe} 13-\mathrm{x}-\mathrm{yCoy})$ Six Compounds near Room Temperature.” Journal of Applied Physics 106 (2): 23902. doi:10.1063/1.3172927.

Bangarusampath, D.S., Holger Ruckdäschel, Volker Altstädt, Jan K.W. Sandler, Didier Garray, and Milo S.P. Shaffer. 2009. "Rheology and Properties of Melt-Processed Poly(ether Ether Ketone)/multi-Wall Carbon Nanotube Composites." Polymer 50 (24): 5803-11. doi:10.1016/j.polymer.2009.09.061.

Breitenbach, J.. 2002. "Melt Extrusion: From Process to Drug Delivery Technology." European Journal of Pharmaceutics and Biopharmaceutics 54 (2): 107-117.

Brück, E., O. Tegus, L. Zhang, X.W. Li, F.R. de Boer, and K.H.J. Buschow. 2004. "Magnetic Refrigeration near Room Temperature with Fe2P-Based Compounds." Journal of Alloys and Compounds 383 (1-2): 32-36. doi:10.1016/j.jallcom.2004.04.042.

Cheng, H., and I. Manas-Zloczower. 1997. "Study of Mixing Efficiency in Kneading Discs of Co-Rotating Twin-Screw Extruders.” Polymer Engineering \& Science 37 (6): 1082-1090.

Dan'Kov, S. Yu, A. M. Tishin, V. K. Pecharsky, K. A. Gschneidner. 1998. "Magnetic Phase Transitions and the Magnetothermal Properties of Gadolinium.” Physical Review B 57 (6): 3478.

Demers, V., S. Turenne, and O. Scalzo. 2015. "Segregation Measurement of Powder Injection Molding Feedstock Using Thermogravimetric Analysis, Pycnometer Density and Differential Scanning Calorimetry Techniques.” Advanced Powder Technology 26 (3): 997-1004. doi:10.1016/j.apt.2015.04.005.

Duarte, M. V., L. C. Pires, P. D. Silva, and P. D. Gaspar. 2015. "Current and Future Trends of Refrigerants Development." Handbook of Research on Advances and Applications in Refrigeration Systems and Technologies, 207.

Claudel D., M. Sahli, T. Barriere, J.C. Gelin, 2017, Influence of particle-size distribution and temperature on the rheological properties of highly concentrated Inconel feedstock alloy 718, Powder Technology, 322, 273-289.

Dubrez, A., P. Vikner, C. Mayer, and M. Pierronnet. 2013. Procédé de fabrication d'un élément magnétocalorique, et élément magnétocalorique ainsi obtenu. WO 2013/135908 Al, issued September 2013.

Fayyaz, A., N. Muhamad, A. B. Sulong, H. S. Yunn, S.Yulis M. Amin, and J. Rajabi. 2015. "Micro-Powder Injection Molding of Cemented Tungsten Carbide: Feedstock Preparation and Properties." Ceramics International 41 (3): 3605-12. doi:10.1016/j.ceramint.2014.11.022. 
Franco V., J.S. Blázquez, J.J. Ipus, J.Y. Law, L.M. Moreno-Ramírez, A. Conde. 2018. Magnetocaloric effect: From materials research to refrigeration devices, Progress in Materials Science, 93, 112-232.

Gschneidner Jr, K. A., V. K. Pecharsky, and A O Tsokol. 2005. "Recent Developments in Magnetocaloric Materials." Reports on Progress in Physics 68 (6): 1479-1539. doi:10.1088/0034-4885/68/6/R04.

Jacobs, S., J. Auringer, A. Boeder, J. Chell, L. Komorowski, J. Leonard, S. Russek, and C. Zimm. 2014. “The Performance of a Large-Scale Rotary Magnetic Refrigerator.” International Journal of Refrigeration 37 (January): 84-91. doi:10.1016/j.ijrefrig.2013.09.025.

Kalaprasad, G., G. Mathew, C. Pavithran, and Sabu Thomas. 2003. "Melt Rheological Behavior of Intimately Mixed Short Sisal-glass Hybrid Fiber-Reinforced Low-Density Polyethylene Composites. I. Untreated Fibers.” Journal of Applied Polymer Science 89 (2): 432-442.

Lanzarini, J., T. Barriere, J. C. Gelin, A. Dubrez, C. Mayer, M. Pierronnet, and P. Vikner. 2015. "Thermoplastic Filled with Magnetocaloric Powder.” Materials \& Design. doi:10.1016/j.matdes.2015.08.057.

Liang, M., H. E. Huff, and F.-H. Hsieh. 2002. "Evaluating Energy Consumption and Efficiency of a Twin-Screw Extruder.” Journal of Food Science 67 (5): 1803-1807.

Ma, J., M. Qin, L. Zhang, L.Tian, R. Li, P. Chen, and X. Qu. 2014. "Effect of Ball Milling on the Rheology and Particle Characteristics of Fe-50\%Ni Powder Injection Molding Feedstock.” Journal of Alloys and Compounds 590 (March): 41-45. doi:10.1016/j.jallcom.2013.12.080.

Mayer, C., A. Dubrez, M. Pierronnet, and P. Vikner. 2014. "Towards the Large Scale Production of $\left(\mathrm{La}_{1-\mathrm{Z}} \mathrm{Ce}_{\mathrm{z}}\right)\left(\mathrm{Fe}_{1-\mathrm{X}-}\right.$ y $\left.\mathrm{Mn}_{\mathrm{y}} \mathrm{Si}_{\mathrm{x}}\right)_{13} \mathrm{H}_{\mathrm{n}}$ Products for Room Temperature Refrigeration: Towards the Large Scale Production of (La 1-Z $\left.\mathrm{Ce}_{\mathrm{z}}\right)\left(\mathrm{Fe}_{1-\mathrm{X}-\mathrm{Y}} \mathrm{Mn}_{\mathrm{y}} \mathrm{Si}_{\mathrm{x}}\right)_{13} \mathrm{H}_{\mathrm{n}}$ Products for Room Temperature Refrigeration.” Physica Status Solidi (c) 11 (5-6): 1059-63. doi:10.1002/pssc.201300650.

Meinshausen, M., N. Meinshausen, W. Hare, S. C. B. Raper, K. Frieler, R. Knutti, D. J. Frame, and M. R. Allen. 2009. “Greenhouse-Gas Emission Targets for Limiting Global Warming to $2{ }^{\circ} \mathrm{C} . ”$ Nature 458 (7242): 1158-62. doi:10.1038/nature08017.

Phejar, M., V. Paul-Boncour, and L. Bessais. 2010. "Structural and Magnetic Properties of Magnetocaloric LaFe13xSix Compounds Synthesized by High Energy Ball-Milling." Intermetallics 18 (12): 2301-7. doi:10.1016/j.intermet.2010.07.022.

Pracella, Mariano, Donatella Chionna, Irene Anguillesi, Zbigniew Kulinski, and Ewa Piorkowska. 2006. "Functionalization, Compatibilization and Properties of Polypropylene Composites with Hemp Fibres." Composites Science and Technology 66 (13): 2218-30. doi:10.1016/j.compscitech.2005.12.006. 
Pulko, B., J. Tušek, J. D. Moore, B. Weise, K. Skokov, O. Mityashkin, A. Kitanovski, 2015. “Epoxy-Bonded La-FeCo-Si Magnetocaloric Plates.” Journal of Magnetism and Magnetic Materials 375 (February): 65-73. doi:10.1016/j.jmmm.2014.08.074.

Romero Gómez, J., R. Ferreiro Garcia, J. Carbia Carril, and M. Romero Gómez. 2013. “A Review of Room Temperature Linear Reciprocating Magnetic Refrigerators.” Renewable and Sustainable Energy Reviews 21 (May): 1-12. doi:10.1016/j.rser.2012.12.018.

Rosendahl Hansen, B., L. Theil Kuhn, C.R.H. Bahl, M. Lundberg, C. Ancona-Torres, and M. Katter. 2010. "Properties of Magnetocaloric $\mathrm{La}(\mathrm{Fe}, \mathrm{Co}, \mathrm{Si}) 13$ Produced by Powder Metallurgy." Journal of Magnetism and Magnetic Materials 322 (21): 3447-54. doi:10.1016/j.jmmm.2010.06.043.

Sedlacek, T., M. Zatloukal, P. Filip, A. Boldizar, and P. Saha. 2004. "On the Effect of Pressure on the Shear and Elongational Viscosities of Polymer Melts.” Polymer Engineering \& Science 44 (7): 1328-1337.

Thiébaud, F., and J.C. Gelin. 2010. "Characterization of Rheological Behaviors of Polypropylene/carbon Nanotubes Composites and Modeling Their Flow in a Twin-Screw Mixer.” Composites Science and Technology 70 (4): 647-56. doi:10.1016/j.compscitech.2009.12.020.

Tishin, A. M., and Y. I. Spichkin. 2003. The Magnetocaloric Effect and Its Applications. Series in Condensed Matter Physics. Bristol: Inst. of Physics Publ.

Tura, A., K. K. Nielsen, and A. Rowe. 2012. "Experimental and Modeling Results of a Parallel Plate-Based Active Magnetic Regenerator.” International Journal of Refrigeration $35 \quad$ (6): 1518-27. doi:10.1016/j.ijrefrig.2012.04.016.

Villmow, T., B. Kretzschmar, and P. Pötschke. 2010. "Influence of Screw Configuration, Residence Time, and Specific Mechanical Energy in Twin-Screw Extrusion of Polycaprolactone/multi-Walled Carbon Nanotube Composites.” Composites Science and Technology 70 (14): 2045-55. doi:10.1016/j.compscitech.2010.07.021.

N. Yang, Y. Caiyin, T. Na, Z. Yue, L. Haiyan, H. Jun, 2018, Simultaneous plate forming and hydriding of La(Fe, Si) 13 magnetocaloric powders, Journal of Magnetism and Magnetic Materials, 451, 47-50.

Pengna Z., L. Jian, S. Yanyan, Y. Aru, 2017, Direct formation of NaZn13-structure La(Fe, Si) 13 phase by directional solidification, Materials Letters, 193, 34-37.

Weiland S., F. Petzoldt, 2017, Powder-extrusion and sintering of magnetocaloric LaCe(FeMnSi) ${ }_{13}$ alloy, Journa of Alloys and Compounds, 719, 182-188. 
active magnetic regenerator

magnetocaloric effect

polypropylene

low-density polyethylene

thermogravimetric analysis

differential scanning calorimetry

Curie temperature

specific surface area

melt flow rate
AMR

MCE

PP

LDPE

TGA

DSC

$\mathrm{T}_{\mathrm{c}}$

SSA

MFR 